\title{
Vascular memory: can we broaden the concept of the metabolic memory?
}

\author{
György Jermendy*
}

\begin{abstract}
Based on the results of recent randomized, controlled clinical trials and analyses of their follow-up periods the concept of metabolic memory cannot be restricted to antihyperglycaemic treatment only, rather it can be extended to lipid-lowering and antihypertensive treatment and even life-style modification. This broadened concept can be designated as vascular memory. According to this new concept, not only immediate and short-term but long-term effects of the metabolic and cardiovascular risk milieu are of great importance. Consequently, early and intensive lifestyle interventions, treatment of hyperglycaemia, lipid abnormalities and hypertension can result in beneficial effects on cardiovascular outcomes even in the long run. On the contrary, failing in target-oriented treatment from early detection of abnormalities can be associated with life-threatening cardiovascular events subsequently. Additional experimental studies are needed to characterize the exact pathomechanism of vascular memory and further clinical trials are also essential to explore its real clinical significance.
\end{abstract}

Keywords: Metabolic memory, Metabolic legacy, Vascular memory, Cardiovascular diseases

The concept of metabolic memory was first described among patients with type 1 diabetes in 2005, based on the results of the follow-up observation of the original cohort in the DCCT [1]. Although this term was already used in former experimental diabetes models and studies with isolated cells as early as the mid-1980s [2], the modern concept of metabolic memory emerged from the DCCT-EDIC. Reassuringly, late effect of previous antihyperglycaemic treatment was documented among patients with type 2 diabetes during the follow-up of the original cohort in the UKPDS [3]. The phenomenon was designated as metabolic legacy. Based on the results of recent randomized, controlled clinical trials and analyses of their follow-up periods it became obvious that the concept of metabolic memory cannot be restricted to antihyperglycaemic treatment only.

In this paper, clinical evidence concerning the late effect of antihyperglycaemic treatment is summarized. Additionally, the late effects of lipid-lowering and antihypertensive treatment as well as life-style modification are also reviewed. Taken together, results from recent clinical trials suggest that the original concept of metabolic memory can be defined in a much broader context.

Correspondence: gyjermendy@mail.datanet.hu

Teaching Department of Internal Medicine, Bajcsy-Zsilinszky Hospital, Maglódi út, 89-911106, Budapest, Hungary

\section{Antihyperglycaemic treatment and its late effect in type 1 diabetes}

The DCCT was a multicenter, randomized, controlled clinical trial which compared intensive insulin therapy with conventional insulin regimens in patients with type 1 diabetes [4]. Originally, 1441 patients with type 1 diabetes were randomly assigned to either intensive or conventional insulin therapy and were followed for a mean of 6.5 years between 1983 and 1993. A significant difference in HbA1c values of the groups was found (mean values in patients with intensive treatment $7.4 \%$ and that in patients with conventional treatment $9.0 \%, \mathrm{p}<0.001$ ). The risk of both development and progression of microvascular complications was significantly reduced by intensive insulin treatment. Nevertheless, due to the low incidence of cardiovascular events only a decreasing trend in risk of macrovascular complications was observed during the trial. The EDIC trial was a longitudinal observational study involving the cohort from the DCCT. The goal of this observational prospective evaluation was to assess the long-term effects of differences in prior treatment (intensive versus conventional insulin therapy during the DCCT) on the late development and progression of microvascular and macrovascular complications [5]. Although the absolute difference in HbA1c values between \\ () Biomed Central}

(C) 2012 Jermendy; licensee BioMed Central Ltd. This is an Open Access article distributed under the terms of the Creative Commons Attribution License (http://creativecommons.org/licenses/by/2.0), which permits unrestricted use, distribution, and reproduction in any medium, provided the original work is properly cited. 
the groups was only $0.1 \%(\mathrm{p}=0.38)$ at year 11 in the EDIC study, a consistent salutary effect of intensive insulin therapy was observed. Namely, by achieving glucose control as close to the nondiabetic range as safely possible, the risk of development and progression of micro- and macrovascular late complications was significantly reduced.

As for microvascular complications, the risk of retinopathy remained significantly reduced in the former group with intensive insulin treatment 4 years after completion of the original trial [6]. In addition, after 10 years in the DCCIT/EDIC follow up the rates of retinopathy proved to be lower than in the former group with conventional insulin treatment despite the converged $\mathrm{HbA1c}$ levels during the follow-up [7]. As for diabetic nephropathy, a reduction of microalbuminuria and clinical albuminuria was observed at 8 years of the follow-up. In addition, fewer cases with hypertension and transplantation due to diabetic nephropathy were recorded [8]. At a median follow-up of 13 years after persistent microalbuminuria, former intensive diabetes therapy proved to be associated with improved renal outcomes such as progression to microalbuminuria, impaired glomerular filtration rate, end-stage renal disease and regression to normoalbuminuria [9]. Over a median follow-up period of 22 years in the combined study (at a median follow-up of 16 years in the EDIC study) impairment of the glomerular filtration rate (GFR) developed in 24 participants assigned to intensive therapy and in 46 assigned to conventional therapy resulting in a $50 \%$ risk reduction with intensive therapy (95 \% CI 18-69; $\mathrm{p}=0.0006$ ) [10]. As for neuropathy, signs of both somatic and autonomic neuropathy were less frequently observed in patients with early intensive glycaemic control in the DCCT/EDIC follow-up at 8 years [11]. Moreover, the benefits of former intensive insulin treatment persisted for 13-14 years after the DCCT closeout and provide evidence of a durable effect of prior intensive treatment on both peripheral [12] and autonomic neuropathy [13].

As for cardiovascular complications, a beneficial effect of early intensive glycaemic control on surrogate endpoints such as progression of carotid intima-media thickness $[14,15]$ or coronary artery calcification $[16]$ was also shown during the EDIC follow-up at 6 and at 7-9 years, respectively. A beneficial effect on cardiovascular events was also documented [1]. Namely, during the mean 17 years of follow-up, 46 cardiovascular events occurred in 31 patients who had received intensive treatment in the DCCT, as compared with 98 events in 52 patients who had received conventional treatment. Intensive treatment reduced the risk of any cardiovascular disease event by $42 \%$ (95\% CI 9 to $63 \% ; \mathrm{p}=0.02)$ and the risk of nonfatal myocardial infarction, stroke, or death from cardiovascular disease by $57 \%$ (95\% CI 12 to $79 \%$; $\mathrm{p}=0.02$ ).

Taken together, the DCCT/EDIC study demonstrated that an average period of 6.5 years of intensive insulin treatment had a long-term, sustained effect on the subsequent risk of late micro- and macrovascular complications (Figure 1). This phenomenon was designated by the authors as „metabolic memory” in 2005 [1].

\section{Antihyperglycaemic treatment and its late effect in type 2 diabetes}

The UKPDS, one of the largest randomised clinical trials in diabetology, embracing 20 years of study (1977-1997) followed by a further 10 years of post-trial monitoring, has radically altered our knowledge about the natural course and treatment of type 2 diabetes. The original trial with 4209 randomized patients documented that intensive glucose therapy versus conventional treatment (i.e. better glycaemic control) was associated with a reduced risk of clinically evident microvascular complications and a nonsignificant reduction in the relative risk of myocardial infarction in patients with newly diagnosed type 2 diabetes mellitus [17]. In the post-trial monitoring, 3277 patients were asked to attend annual UKPDS clinics for 5 years and later questionnaires were used to follow patients in years 6 to 10. Between-group differences in glycated hemoglobin levels were lost after at the first year after closeout. In the sulfonylurea/insulin group, relative reductions in risk persisted at 10 years for any diabetesrelated end point and microvascular disease. In addition, as more events occurred, risk reductions for myocardial infarction and death from any cause emerged (Table 1). Similarly, a continued benefit after metformin therapy was also evident among overweight patients. In conclusion, a beneficial effect of better glycaemic control due to intensive treatment persisted over time despite the early loss of within-trial differences in glycated hemoglobin levels between the intensive-therapy group and the conventionaltherapy group. The phenomenon was called as legacy effect of earlier glucose control [3].

\section{Lipid lowering treatment with statins and its late effect}

The legacy effect of lipid lowering treatment was documented by extended follow-up investigations of randomized controlled trials with statins (simvastatin, pravastatin, atorvastatin) supporting the idea of vascular memory.

The $4 \mathrm{~S}$ was one of the earliest randomized trials for assessing the effect of simvastatin in the secondary prevention of myocardial infarction [18]. The benefits of simvastatin in reducing mortality and cardiovascular events were clearly demonstrated in this study (median duration of follow-up 5.4 years). After completion, patients were followed for an additional 2 years (interim analysis), and later for 5 years during which open-label simvastatin treatment was provided for all patients $[19,20]$. It was found that simvastatin treatment for 5.4 years in a placebo-controlled trial, followed by open-label statin therapy for 5 years, was 


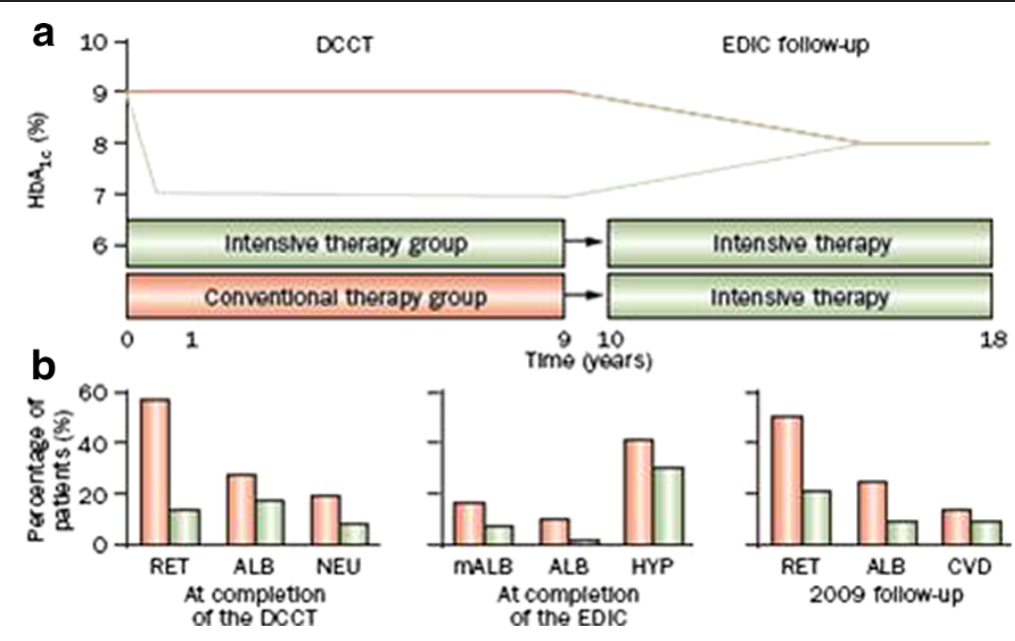

Figure 1 The design of the DCCT-EDIC study and the development of late complications (From Nat Rev Endocrinol 2010; 6:665-675, with permission of the publisher [Nature Publishing Group]). RET: retinopathy, ALB: albuminuria, NEU: neuropathy, mALB: microalbuminuria, HYP: hypertension, CVD: cardiovascular diseases.

associated with a survival benefit over 10 years of follow-up compared with open-label statin therapy for the past 5 years only. It is of note, that during the post-trial period there were no differences in cardiovascular event rates in those originally assigned simvastatin or placebo but importantly, the survival benefit of patients allocated simvastatin compared with those allocated placebo that accrued during the double-blind trial period persisted during follow-up.

In the HPS, the efficacy and safety of lowering LDLcholesterol with daily $40 \mathrm{mg}$ simvastatin (versus placebo) were investigated [21]. During the in-trial period (mean follow-up 5.3 years), allocation to simvastatin yielded an average reduction in LDL cholesterol of $1.0 \mathrm{mmol} / \mathrm{l}$ and a proportional decrease in major vascular events of $23 \%$ (95 \% CI 19-28; $\mathrm{p}<0.0001$ ). During the post-trial period of 6.7 years (when statin use and lipid concentrations were similar in both groups), no further significant reductions were noted in either major vascular events (risk ratio 0.95 [95 \% CI 0.89-1.02]) or vascular mortality (0.98 [95 \% CI 0.90-1.07]). Nevertheless, the substantial

\begin{tabular}{|c|c|c|c|c|}
\hline \multirow{2}{*}{ Aggregate endpoint } & \multicolumn{2}{|l|}{1997} & \multicolumn{2}{|l|}{2007} \\
\hline & RRR & $\mathrm{p}$ value & RRR & $p$ value \\
\hline Any diabetes related endpoint & $12 \%$ & 0.029 & $9 \%$ & 0.040 \\
\hline Microvascular disease & $25 \%$ & 0.0099 & $24 \%$ & 0.001 \\
\hline Myocardial infarction & $16 \%$ & 0.052 & $15 \%$ & 0.014 \\
\hline All-cause mortality & $6 \%$ & 0.44 & $13 \%$ & 0.007 \\
\hline
\end{tabular}

reduction in vascular events among patients allocated simvastatin compared with those allocated placebo that was found in the randomized period of the trial persisted during observational follow-up after closeout of the original trial [22].

The WOSCOPS was designed to determine whether pravastatin in men with hypercholesterolaemia and no history of myocardial infarction reduced the combined incidence of nonfatal myocardial infarction and death from coronary heart disease [23]. After randomisation, patients were treated with either pravastatin or placebo for an average follow-up period of 4.9 years. In the double-blind phase of the trial, a $31 \%$ relative risk reduction $(\mathrm{p}<0.001)$ of combined endpoint was observed. The results of the long-term follow-up of the WOSCOPS were published later [24]. In the 10-year-long observational period, pravastatin was provided for all participants alive at the completion of the double blind phase. As for primary combined endpoint, the relative risk reduction favouring pravastatin was $18 \%(p=0.02)$ in the observational period while it was $27 \%(\mathrm{p}<0.001)$ in the entire investigation $(5$ year doubleblind phase +10 year observational follow-up). Taken together, 5 years of treatment with pravastatin was associated with a significant reduction in coronary events for a subsequent 10 years in men with hypercholesterolaemia but without a history of myocardial infarction.

The LIPID trial was designed to evaluate the effect of pravastatin (40 mg daily) versus placebo in 9014 patients (age 31-75 years) with a history of myocardial infarction or hospitalization for unstable angina and initial plasma total cholesterol levels of $4.0-7.0 \mathrm{mmol} / \mathrm{l}$ [25]. The mean follow-up was 6.0 years. The relative risk reduction of death from coronary heart disease favouring pravastatin was $24 \%(\mathrm{p}<0.001)$. After closing the double blind phase, the 
patients were followed for a further 2 years [26]. During this observational period, pravastatin was provided for participants treated formerly with placebo. In this period, no difference in plasma LDL-cholesterol values of the two groups was observed (Figure 2). Nevertheless, KaplanMeier curves of cardiovascular events and total mortality continuously diverged favouring the originally active versus control arms despite conversion of curves representing the changes of LDL-cholesterol values over time (Figure 3).

The ASCOT-LLA was a placebo-controlled randomized trial for evaluating the effects of atorvastatin $10 \mathrm{mg}$ daily in the primary prevention of coronary heart disease in hypertensive subjects who had a total cholesterol level of $\leq 6.5 \mathrm{mmol} / \mathrm{l}$. The trial was stopped prematurely after a median 3.3-year follow-up due to substantial benefits of atorvastatin ( $36 \%$ relative risk reduction) on composite primary endpoint of cardiovascular events [27]. The results of extended observations 2.2 years after trial closure were published in 2008 [28] while those of the 11-year follow-up became available in 2011 [29]. At 2.2 years after the end of the ASCOT-LLA, the relative risk reduction in all endpoints remained essentially unchanged, although extensive crossovers from and to statin usage occurred. At 8 years after closure of ASCOT-LLA, all-cause mortality remained significantly lower in those originally assigned atorvastatin (HR 0.86, $95 \%$ CI 0.76-0.98, p =0.02). Cardiovascular deaths were fewer, but not significant (HR 0.89, 95 \% CI 0.72-1.11, $\mathrm{p}=0.32$ ) and non-cardiovascular deaths were significantly lower (HR 0.85, 95 \% CI 0.73-0.99, p=0.03) in those formerly assigned atorvastatin attributed to a reduction in deaths due to infection and respiratory illness. The authors concluded that a legacy effect of those originally assigned atorvastatin might contribute to long-term benefits on all-cause mortality.

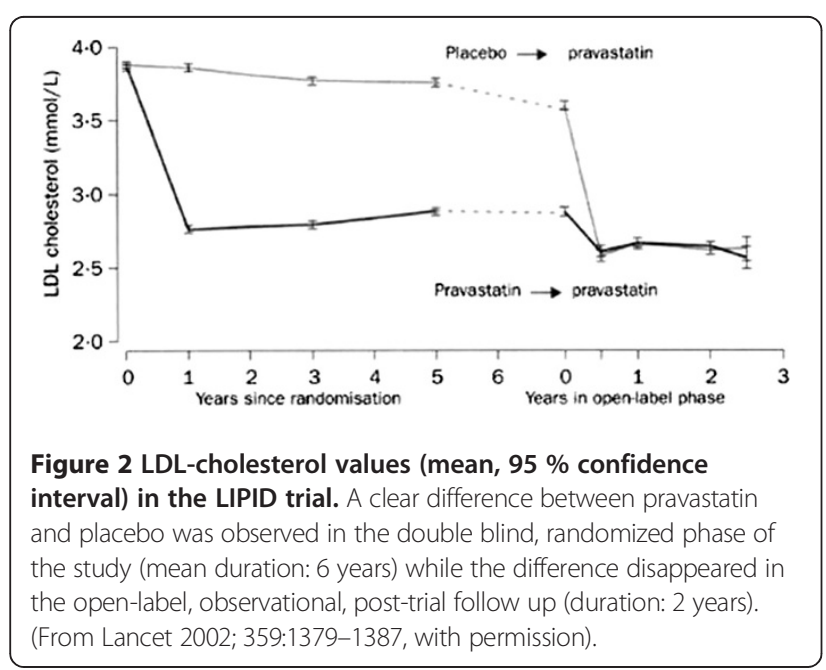

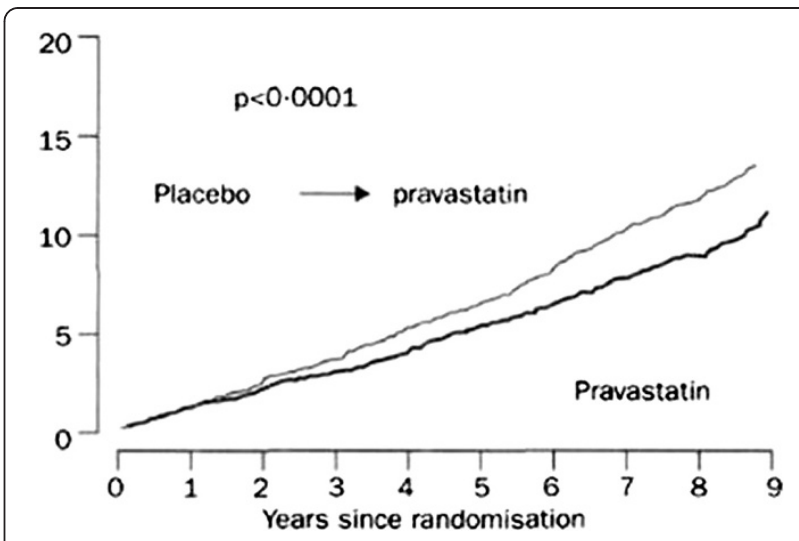

Figure 3 Kaplan-Meier estimates illustrating the primary outcome (death from coronary artery disease [\%]) in the LIPID trial. In the double blind phase of the trial (mean duration: 6.0 years) a clear difference between pravastatin and placebo occurred which was maintained in the open, post-trial observational follow-up period (duration: 2.0 years) (From Lancet 2002; 359: 1379-1387, with permission)

\section{Treatment with antihypertensive drugs and its late effect}

The legacy effect of treatment with antihypertensive drugs was observed in some randomized, controlled trials with post-trial observational follow-up. Nevertheless, the beneficial late effect of tighter antihypertensive control was not observed in the UKPDS 10-year follow-up.

In the HOPE study, the effect of ramipril versus placebo was assessed in patients who were at high risk for cardiovascular events but who did not have left ventricular dysfunction or heart failure [30]. A total of 9297 patients (age $\geq 55$ years) were randomly assigned to receive ramipril (10 mg once per day) or matching placebo for a mean of 4.5 years. The primary outcome was a composite of myocardial infarction, stroke, or death from cardiovascular causes. A total of 651 patients who were assigned to receive ramipril (14.0 percent) reached the primary end point, as compared with 826 patients who were assigned to receive placebo (17.8 percent) (relative risk 0.78 ; $95 \%$ confidence interval, 0.70 to $0.86 ; \mathrm{p}<0.001$ ). The participants of the HOPE trial were followed up after terminating the original double blind phase for an additional 2.6 years in order to assess whether the benefits were maintained after trial cessation. During the extended follow-up (HOPE-TOO trial), in those who were event-free at the end of the HOPE study, there was a trend toward a further reduction in major cardiovascular events [31]. During the entire 7.2 years of follow-up, there was a significant risk reduction with ramipril for the primary composite outcome of myocardial infarction, stroke and cardiovascular death (relative risk reduction $17 \%, \mathrm{p}=0.0002$ ) (Figure 4).

In the TRACE study, patients with myocardial infarction and left ventricular systolic dysfunction (ejection 


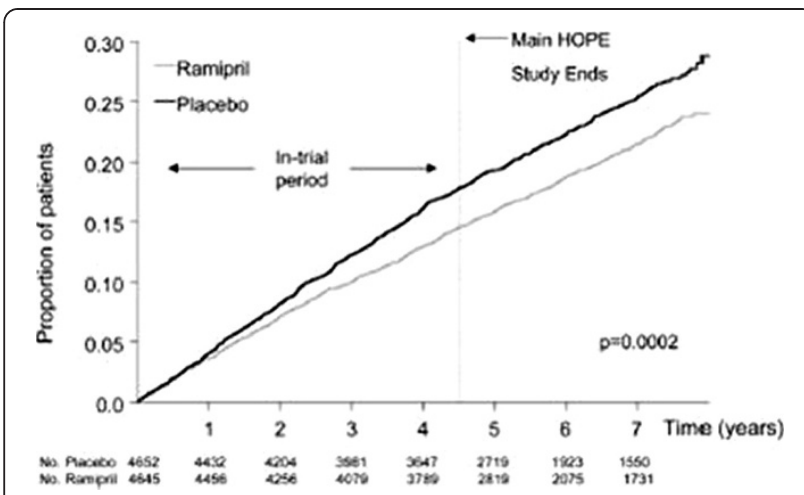

Figure 4 Kaplan-Meier estimates of the composite outcome of myocardial infarction, stroke, or cardiovascular death in the ramipril group and the placebo group of the HOPE trial and its extension (HOPE-TOO) (From Circulation 2005; 112:1339-1346, with permission).

fraction $\leq 35 \%)$ were randomly assigned to receive oral trandolapril or placebo [32]. The follow-up was 24 to 50 months. The relative risk reduction of death in the trandolapril versus placebo group was $22 \%(\mathrm{p}=0.001)$. The long-term benefit of trandolapril was evaluated over 10-12 years of follow-up [33]. In the post-treatment period no difference was observed between groups (relative risk $1.03, \mathrm{p}=0.75$ ) regarding all-cause mortality but for the entire follow-up, trandolapril significantly reduced the risk of death compared with placebo (relative risk reduction $11 \%, \mathrm{p}=0.031$ ). The authors concluded that in patients with left ventricular dysfunction, trandolapril given shortly after a myocardial infarction for 2-4 years has long-term benefits on mortality maintained for at least $10-12$ years.

In the SOLVD trial, enalapril versus placebo was added to conventional therapy in patients with reduced $(\leq 35 \%)$ ejection fraction and a significant reduction in the incidence of heart failure and the rate of related hospitalizations was observed in a median duration of 37.4 months. In addition, there was a trend toward fewer deaths due to cardiovascular causes among the patients who received enalapril [34]. In order to establish whether the mortality reduction with enalapril was sustained, subsequent vital status was ascertained in 5165 individuals who were alive when the trial had been completed. The duration of the total follow-up was 12.1 years [35]. Beyond the original trial period, the survival curves continued to diverge in favour of the enalapril group for about 5 years, after which the curves started to converge. The authors concluded that the benefits of enalapril treatment continued to accrue beyond the end of the trial resulting in a sustained improvement in survival.

In the SYST-EUR study, elderly patients with isolated systolic hypertension after 2 years of randomized treatment with nitrendipine or placebo were followed for an additional 4 years with open-label antihypertensive treatment [36]. Patients who received early antihypertensive treatment, as compared with patients who initially received placebo, had a significantly greater reduction in the risk of stroke (28\%), cardiovascular complications $(15 \%)$ and total mortality (13\%). The benefits were even more pronounced in diabetic patients.

In the UKPDS with newly diagnosed type 2 diabetic patients, the effect of tight blood pressure control was also evaluated and, therefore, over a 4-year period 1148 patients with hypertension were randomized to tight or less-tight blood-pressure control regimens. Tight control was achieved by using ACE-inhibitor (captopril) or betablocker (atenolol) while less-tight control was maintained by antihypertensive treatment that excluded these agents. In the randomized trial, for tight as compared with the less-tight control of blood pressure, there were relative risk reductions of $24 \%$ for any diabetes-related endpoint, $32 \%$ for diabetes-related death, $44 \%$ for stroke, and $37 \%$ for microvascular disease [37]. During the 10-year post-interventional period, differences in blood pressure between the two groups during the trial disappeared within 2 years after termination of the trial and the benefits of previously improved blood pressure control were not sustained when between-group differences in blood pressure were lost [38].

\section{Lifestyle modification and its late effect}

In the FDPS, 522 middle-aged, overweight subjects with impaired glucose tolerance were randomly assigned to either the intervention or the control group [39]. Each subject in the intervention group received individualized counselling aimed at reducing weight, total intake of fat, and intake of saturated fat and increasing intake of fiber and physical activity. The primary end point was the development of type 2 diabetes, the duration of follow-up was 3.2 years. The cumulative incidence of diabetes after four years was $11 \%$ in the intervention group and $23 \%$ in the control group. Overall, the risk of diabetes was $58 \%$ lower $(\mathrm{p}<0.001)$ in the intervention group than in the control group. After the active intervention period, participants who were still free of diabetes were further followed-up for a median of 3 years [40]. Beneficial changes achieved by participants in the intervention group were maintained after discontinuation of the intervention, and the corresponding incidence rates during the post-intervention follow-up were 4.6 and 7.2 per 100 person-years $(\mathrm{p}=0.0401)$, indicating $36 \%$ reduction in relative risk. Nevertheless, the active intervention period did not decrease the risk of cardiovascular morbidity and mortality during the first 10 years of follow-up [41].

In the China Da Qing Diabetes Prevention Study, 577 adult subjects with impaired glucose tolerance were 
randomly assigned to either the control group or to lifestyle intervention groups (diet, exercise, or both). Active intervention took place between 1986 and 1992 [42]. In 1992, after a 6-year intervention, participants were informed of the final results and asked to continue with normal medical care. In 2006, study participants were followed-up to assess the long-term effect of intervention [43]. Compared with control participants, those in the combined lifestyle intervention groups had a $51 \%$ lower incidence of diabetes (hazard ratio 0.49; $95 \%$ CI 0.33 0.73 ) during the active intervention period and a $43 \%$ lower incidence (hazard ratio 0.57; 95 \% CI 0.41 - 0.81) over the 20 year period.

In the 2.8 years of the DPP randomised clinical trial, diabetes incidence in high-risk adults was reduced by $58 \%$ with intensive lifestyle intervention and by $31 \%$ with metformin, compared with placebo [44]. During the 10-year follow-up since randomisation, incidences in the former placebo and metformin groups fell to equal those in the former lifestyle group, but the cumulative incidence of diabetes remained lowest in the lifestyle group. Accordingly, prevention or delay of diabetes with lifestyle intervention or metformin persisted for at least 10 years [45].

\section{Multifactorial intervention and its late effect}

The STENO-2 study, conducted over 7.8 years, recognized that the risk of cardiovascular events and death could be halved among patients with longstanding diabetes and microalbuminuria by intensive multifactorial treatment [46]. Patients from this cohort were subsequently followed for a mean of 5.5 years and results from this post-trial observation documented that intensive intervention had sustained beneficial effects with respect to vascular complications and death (Figure 5) [47].

\section{Possible pathomechanism}

Although the exact pathomechanism of vascular memory is not clearly understood some elements of the pathophysiologic process have already been highlighted by experimental studies. Furthermore, explanations of the late effect of an earlier treatment have become available from clinical studies.

As for antihyperglycaemic treatment, increased formation of AGE could be a plausible cause of structural and functional changes occurring in the early metabolic environment but carrying implications for developing and progressing micro- and macrovascular complications in the long run [48-50]. In addition, altered mitochondrial function due to oxidative stress should also be considered [51]. Recently, increasing evidence suggests that epigenetic factors play a key role in the complex interplay between genes and the environment [52]. Thus, sustained hyperglycaemia can lead via methylation or histone acetylation to dysregulated epigenetic mechanisms that affect chromatin

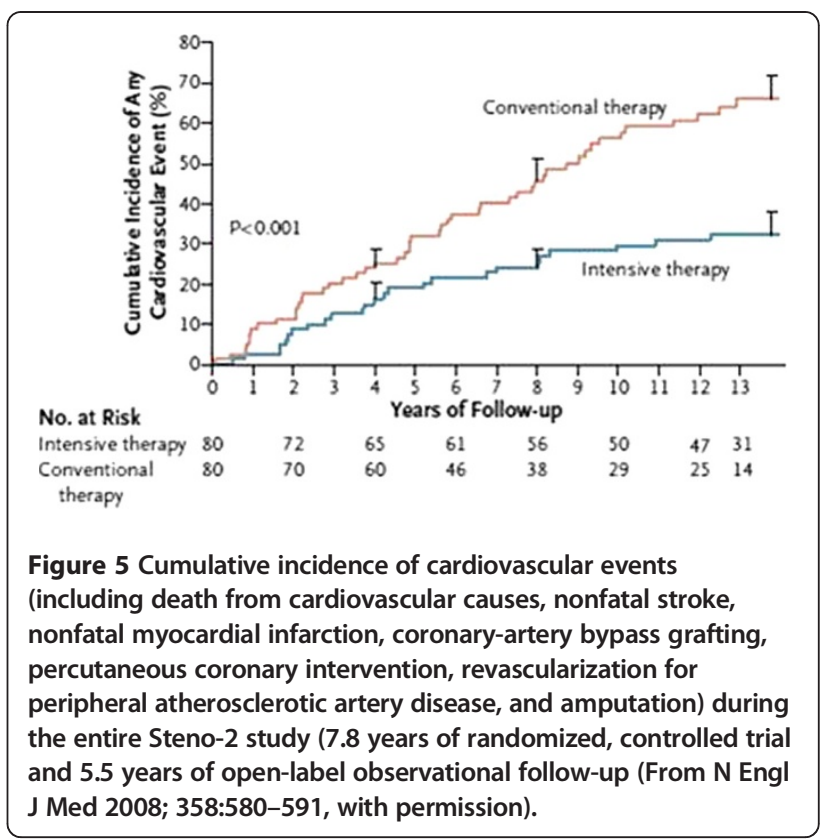

structure and gene expression [53-57]. Accordingly, the altered state of the epigenome might be the underlying mechanism contributing to the metabolic memory resulting in micro- and macrovascular dysfunction in diabetes even after achieving adequate glycaemic control. Nevertheless, it was found in a further experimental study that exposure to oscillating glucose was more deleterious than constant high glucose and induced a metabolic memory after glucose normalisation [58]. In clinical circumstances, the role of AGE formation was suggested as a rational basis for the phenomenon of metabolic memory in the DCCT cohort [59]. However, some other elements should also be considered. For example microalbuminuria, a well characterized cardiovascular risk factor, was less pronounced in the intensively treated subgroup during the entire DCCT-EDIC observation which could contribute to the more favourable cardiovascular outcome when subgroups with former intensive versus conventional treatment were compared [9]. Interestingly enough, reanalyzing the DCCT with respect to time-dependent memory effects of HbA1c revealed that the most current (in real time) HbA1c value was not the most important, but values from 2 to 3 years prior contributed the greatest risk to current progression of retinopathy [60]. Recently, links between microvascular dysfunction and subsequent macrovascular disease were supposed and microvascular structural changes were suggested to play a potential role in the metabolic memory [61].

Although late beneficial effect of early therapy with statins was documented in several lipid trials, the patomechanism remains obscure. Although the time of initiating treatment with statins and the dose of the respective statin are of great importance, the non-lipid 
lowering benefits of statins should also be considered. Generally, statins are linked to the inhibition of HMGCoA reductase and a subsequent reduction in synthesis of isoprenoid intermediates by which a number of critical intracellular signalling processes are prevented leading to beneficial effect on subclinical inflammation and endothelial function. All these factors may have a role in vascular protection with statin therapy even long term [62,63].

As for treatment with antihypertensive drugs, it should be emphasized that no legacy effect in the UKPDS followup was observed [38]. Nevertheless, the absence of the legacy effect in the UKPDS hypertension sub-study is heavily debated [64]. It is of note that drugs (captopril or atenolol) used for achieving tight blood pressure control in this sub-study are not really used for long-term blood pressure control in current practice. In addition, the target blood pressure values in the UKPDS were far from those recommended in current guidelines [65]. The sub-study was not really powered to detect the late effect of antihypertensive treatment and the higher HbA1c values in the tight control group might mask the potential benefits during the follow-up. Consequently, no final conclusion can be drawn from the UKPDS hypertension sub-study regarding a legacy effect of antihypertensive treatment. It is of note, however, that results of other clinical trials with antihypertensive drugs (HOPE, TRACE, SOLVD) should be considered supportive for a legacy effect. In this respect it should be noted that RAAS dysregulation is heavily involved in triggering organ damage in patients with diabetes. Hyperglycaemia directly upregulates intracellular synthesis of angiotensin-II and high glucose stimulates angiotensinogen gene expression and cell hypertrophy. Ultimately, angiotensin-II activation leads to pathologic vessel remodelling [66]. In light of these observations, it seems obvious that blocking RAAS and consequently, interfering pathways involved in early organ damage may have late beneficial vascular effect. Conversely, delayed versus immediate start of antihypertensive treatment may have a deleterious effect on cardiovascular outcome [67].

Regarding life-style modification it is of great importance that weight reduction can result in improvement in both insulin resistance and beta-cell function. Accordingly, the incidence rate of diabetes mellitus in subjects originally recruited with impaired glucose tolerance proved to be lower in the intervention versus control groups during the randomized trial and even the posttrial period [68]. In this respect it is of note that some differences in patients' weight between groups were maintained during the follow-up period of the FDPS [69]. Notably, results from studies with life-style modification indicated that incidence of type 2 diabetes rather than that of cardiovascular events decreased during the entire observation $[41,43,45]$.

\section{Summary and practical consequences of the vascular memory}

It is very likely that the term of metabolic memory observed in type 1 and type 2 diabetic patients with different antihyperglycaemic treatment $[70,71]$ can be extended to antihypertensive and lipid-lowering treatment and even life-style modification. This broadened concept can be designated as vascular memory. Some years ago this broadened concept was considered as a hypothesis [72] but with more convincing follow-up data from recent randomized clinical trials it appears very likely that this phenomenon really exists.

According to the concept of the vascular memory, not only immediate and short-term but even long-term effects of the metabolic and cardiovascular risk milieu could be expected. Consequently, early and intensive treatment of hyperglycaemia, lipid abnormalities, and hypertension can result in beneficial effects on cardiovascular outcomes even in the long run ("good memory"). On the contrary, failing in target-oriented treatment from early detection of abnormalities can be associated with subsequent life-threatening cardiovascular events ("bad memory") [73]. Similarly, late beneficial effect of life-style modification (versus regular care) on the incidence of type 2 diabetes was observed among subjects with impaired glucose tolerance. Importantly, ADDITION-Europe is the only randomized trial so far aiming to assess the effect of early intensive intervention of screen-detected patients with type 2 diabetes [74]. At the end of the 5-year prospective study a small, non-significant reduction in the incidence of cardiovascular events and death was observed.

Taken together, the "memory effect" is a new challenge for treatment aiming to reduce cardiometabolic risks and events. It is obvious that not only experimental studies but further clinical trials are needed to explore the exact pathomechanism and the particular clinical significance of the vascular memory.

\begin{abstract}
Abbreviations
ACE: Angiotensin-convertase enzyme; ADDITION-Europe: Anglo-Danish-Dutch Study of Intensive Treatment In People with Screen Detected Diabetes in Primary Care; AGE: Advanced glycation end products; ASCOT-LLA: AngloScandinavian Cardiac Outcomes Trial Lipid Lowering Arm; DCCT: Diabetes Control and Complications Trial; DPP: Diabetes Prevention Program; EDIC: Epidemiology of Diabetes Interventions and Complications; FDPS: Finnish Diabetes Prevention Study; HOPE: Heart Outcomes Prevention Evaluation; HPS: Heart Protection Study; LIPID: Long-term Intervention with Pravastatin in Ischaemic Disease; RAAS: Renin-angiotensin-aldosterone system; SYSTEUR: Systolic Hypertension in Europe Trial; SOLVD: Studies of Left Ventricular Dysfunction; TRACE: Trandolapril Cardiac Evaluation; UKPDS: United Kingdom Prospective Diabetes Study; WOSCOPS: West of Scotland Coronary Prevention Study; 4 S: Scandinavian Simvastatin Survival Study.
\end{abstract}

\section{Competing interests}

The author declares that he has no competing interests.

Author's contribution

GJ conceived, wrote and approved the final manuscript. 
Received: 27 February 2012 Accepted: 30 April 2012

Published: 30 April 2012

\section{References}

1. Nathan DM, Cleary PA, Backlund JY, Genuth SM, Lachin JM, Orchard TJ, Raskin P, Zimmet B, Diabetes Control and Complications Trial/Epidemiology of Diabetes Interventions and Complications (DCCT/EDIC) Research Group: Intensive treatment and cardiovascular disease in patients with type 1 diabetes. N Engl J Med 2005, 353:2643-2653.

2. Ceriello A, Ihnat MA, Thorpe JE: The "metabolic memory": is more than just tight glucose control necessary to prevent diabetic complications? J Clin Endocrinol Metab 2009, 94:410-415.

3. Holman RR, Paul SK, Bethel MA, Matthews DR, Neil HA: 10-year follow-up of intensive glucose control in type 2 diabetes. N Engl J Med 2008, 359:1577-1589.

4. The Diabetes Control and Complications Trial Research Group: The effect of intensive treatment of diabetes on the development and progression of long-term complications in insulin-dependent diabetes mellitus. N Engl J Med 1993, 329:977-986.

5. Epidemiology of Diabetes Interventions and Complications (EDIC): Design, implementation, and preliminary results of a long-term follow-up of the Diabetes Control and Complications Trial cohort. Diabetes Care 1999, 22:99-111.

6. The Diabetes Control and Complications Trial/Epidemiology of Diabetes Interventions and Complications Research Group: Retinopathy and nephropathy in patients with type 1 diabetes four years after a trial of intensive therapy. N Engl J Med 2000, 342:381-389.

7. White NH, Sun W, Cleary PA, Danis RP, Davis MD, Hainsworth DP, Hubbard LD, Lachin JM, Nathan DM: Prolonged effect of intensive therapy on the risk of retinopathy complications in patients with type 1 diabetes mellitus: 10 years after the Diabetes Control and Complications Trial. Arch Ophthalmol 2008, 126:1707-1715.

8. Writing Team for the Diabetes Control and Complications Trial/ Epidemiology of Diabetes Interventions and Complications Research Group: Effect of intensive therapy on the microvascular complications of type 1 diabetes mellitus. JAMA 2002, 287:2563-2569.

9. de Boer $\mathrm{H}$, Rue TC, Cleary PA, Lachin JM, Molitch ME, Steffes MW, Sun W, Zinman B, Brunzell JD, Diabetes Control and Complications Trial/ Epidemiology of Diabetes Interventions and Complications Study Research Group: Long-term renal outcomes of patients with type 1 diabetes mellitus and microalbuminuria: an analysis of the Diabetes Control and Complications Trial/Epidemiology of Diabetes Interventions and Complications cohort. Arch Intern Med 2011, 171:412-420.

10. The DCCT/EDIC Research Group, de Boer IH, Sun W, Cleary PA, Lachin JM, Molitch ME, Steffes MW, Zinman B: Intensive diabetes therapy and glomerular filtration rate in type 1 diabetes. N Engl J Med 2011, 365:2366-2376

11. Martin CL, Albers J, Herman WH, Cleary P, Waberski B, Greene DA, Stevens MJ, Feldman EL, DCCT/EDIC Research Group: Neuropathy among the diabetes control and complications trial cohort 8 years after trial completion. Diabetes Care 2006, 29:340-344

12. Albers JW, Herman WH, Pop-Busui R, Feldman EL, Martin CL, Cleary PA, Waberski BH, Lachin JM, Diabetes Control and Complications Trial/ Epidemiology of Diabetes Interventions and Complications Research Group: Effect of prior intensive insulin treatment during the Diabetes Control and Complications Trial (DCCT) on peripheral neuropathy in type 1 diabetes during the Epidemiology of Diabetes Interventions and Complications (EDIC) Study. Diabetes Care 2010, 33:1090-1096.

13. Pop-Busui R, Low PA, Waberski BH, Martin CL, Albers JW, Feldman EL, Sommer C, Cleary PA, Lachin JM, Herman WH, DCCT/EDIC Research Group: Effects of prior intensive insulin therapy on cardiac autonomic nervous system function in type 1 diabetes mellitus: the Diabetes Control and Complications Trial/Epidemiology of Diabetes Interventions and Complications study (DCCT/EDIC). Circulation 2009, 119:2886-2893.

14. Nathan DM, Lachin J, Cleary P, Orchard T, Brillon DJ, Backlund JY, O'Leary $\mathrm{DH}$, Genuth S, Diabetes Control and Complications Trial, Epidemiology of Diabetes Interventions and Complications Research Group: Intensive diabetes therapy and carotid intima-media thickness in type 1 diabetes mellitus. N Engl J Med 2003, 348:2294-2303.

15. Polak JF, Backlund JY, Cleary PA, Harrington AP, O'Leary DH, Lachin JM Nathan DM, DCCT/EDIC Research Group: Progression of carotid artery intima-media thickness during 12 years in the Diabetes Control and Complications Trial/Epidemiology of Diabetes Interventions and Complications (DCCT/EDIC) study. Diabetes 2011, 60:607-613.

16. Cleary PA, Orchard TJ, Genuth S, Wong ND, Detrano R, Backlund JY, Zinman B, Jacobson A, Sun W, Lachin JM, Nathan DM, DCCT/EDIC Research Group: The effect of intensive glycemic treatment on coronary artery calcification in type 1 diabetic participants of the Diabetes Control and Complications Trial/Epidemiology of Diabetes Interventions and Complications (DCCT/EDIC) Study. Diabetes 2006, 55:3556-3565.

17. UK Prospective Diabetes Study Group: Intensive blood-glucose control with sulphonylureas or insulin compared with conventional treatment and risk of complications in patients with type 2 diabetes (UKPDS 33). Lancet 1998, 352:837-853.

18. The Scandinavian Simvastatin Survival Study Group: Randomized trial of cholesterol lowering in $\mathbf{4 4 4 4}$ patients with coronary heart disease: the Scandinavian Simvastatin Survival Study (4 S). Lancet 1994, 344:1383-1389.

19. Pedersen TR, Wilhelmsen L, Faergeman O, Strandberg TE, Thorgeirsson G, Troedsson L, Kristianson J, Berg K, Cook TJ, Haghfelt T, Kjekshus J, Miettinen $T$, Olsson AG, Pyörälä K, Wedel H: Follow-up study of patients randomized in the Scandinavian simvastatin survival study (4 S) of cholesterol lowering. Am J Cardio/ 2000, 86:257-262.

20. Strandberg TE, Pyörälä K, Cook TJ, Wilhelmsen L, Faergeman O, Thorgeirsson $\mathrm{G}$, Pedersen TR, Kjekshus J: Mortality and incidence of cancer during 10year follow-up of the Scandinavian Simvastatin Survival Study (4 S). Lancet 2004, 364:771-777.

21. Heart Protection Study Collaborative Group: MRC/BHF Heart Protection Study of cholesterol lowering with simvastatin in 20,536 high-risk individuals: a randomised placebo-controlled trial. Lancet 2002, 360:7-22.

22. Heart Protection Study Collaborative Group: Effects on 11-year mortality and morbidity of lowering LDL cholesterol with simvastatin for about 5 years in 20,536 high-risk individuals: a randomised controlled trial. Lancet 2011, 378:2013-2020.

23. Shepherd J, Cobbe SM, Ford I, Isles CG, Lorimer AR, MacFarlane PW McKillop JH, Packard CJ: Prevention of coronary heart disease with pravastatin in men with hypercholesterolemia. West of Scotland Coronary Prevention Study Group. N Engl J Med 1995, 333:1301-1307.

24. Ford I, Murray H, Packard CJ, Shepherd J, Macfarlane PW, Cobbe SM: Longterm follow-up of the West of Scotland Coronary Prevention Study. $N$ Engl J Med 2007, 357:1477-1486.

25. The long-term intervention with pravastatin in ischaemic disease (LIPID) study group: Prevention of cardiovascular events and death with pravastatin in patients with coronary heart disease and a broad range of initial cholesterol levels. N Engl J Med 1998, 339:1349-1357.

26. The long-term intervention with pravastatin in ischaemic disease (LIPID) study group: Long-term effectiveness and safety of pravastatin in 9014 patients with coronary heart disease and average cholesterol concentrations: the LIPID trial follow-up. Lancet 2002, 359:1379-1387. Erratum: Lancet 2002, 360:1430.

27. Sever PS, Dahlöf B, Poulter NR, Wedel H, Beevers G, Caulfield M, Collins R, Kjeldsen SE, Kristinsson A, Mclnnes GT, Mehlsen J, Nieminen M, O'Brien E, Ostergren J, ASCOT investigators: Prevention of coronary and stroke events with atorvastatin in hypertensive patients who have average or lower-than-average cholesterol concentrations, in the AngloScandinavian Cardiac Outcomes Trial-Lipid Lowering Arm (ASCOT-LLA): a multicentre randomised controlled trial. Lancet 2003, 361:1149-1158.

28. Sever PS, Poulter NR, Dahlof B, Wedel H, Beevers G, Caulfield M, Collins R, Kjeldsen SE, Kristinsson A, Mclnnes G, Mehlsen J, Nieminen MS, O'Brien ET, Ostergren J, ASCOT Investigators: The Anglo-Scandinavian Cardiac Outcomes Trial lipid lowering arm: extended observations 2 years after trial closure. Eur Heart J 2008, 29:499-508.

29. Sever PS, Chang CL, Gupta AK, Whitehouse A, Poulter NR, ASCOT Investigators: The Anglo-Scandinavian Cardiac Outcomes Trial: 11-year mortality follow-up of the lipid-lowering arm in the U.K. Eur Heart J 2011 32:2525-2532

30. The Heart Outcomes Prevention Evaluation Study Investigators: Effects of an angiotensin-converting-enzyme inhibitor, ramipril, on cardiovascular events in high-risk patients. N Engl J Med 2000, 342:145-153.

31. Bosch J, Lonn E, Pogue J, Arnold MO, Dagenais GR, Yusuf S, HOPE/HOPETOO Study Investigators: Long-term effects of ramipril on cardiovascular events and on diabetes. Results of the HOPE Study Extension. Circulation 2005, 112:1339-1346. 
32. Køber L, Torp-Pedersen C, Carlsen JE, Bagger H, Eliasen P, Lyngborg K, Videbaek J, Cole DS, Auclert L, Pauly NC: A clinical trial of the angiotensinconverting-enzyme inhibitor trandolapril in patients with left ventricular dysfunction after myocardial infarction. Trandolapril Cardiac Evaluation (TRACE) Study Group. N Engl J Med 1995, 333:1670-1676.

33. Buch $P$, Rasmussen $S$, Abildstrom SZ, Køber L, Carlsen J, Torp-Pedersen C The long-term impact of the angiotensin-converting enzyme inhibitor trandolapril on mortality and hospital admissions in patients with left ventricular dysfunction after a myocardial infarction: follow-up to 12 years. Eur Heart J 2005, 26:145-152.

34. The SOLVD Investigators: Effect of enalapril on mortality and the development of heart failure in asymptomatic patients with reduced left ventricular ejection fractions. N Engl J Med 1992, 327:685-691. Erratum in: N Engl J Med 1992, 327:1768.

35. Jong P, Yusuf S, Rousseau MF, Ahn SA, Bangdiwala SI: Effect of enalapril on 12-year survival and life expectancy in patients with left ventricular systolic dysfunction: a follow-up study. Lancet 2003, 361:1843-1848.

36. Staessen JA, Thijisq L, Fagard R, Celis H, Birkenhäger WH, Bulpitt CJ, de Leeuw PW, Fletcher AE, Forette F, Leonetti G, McCormack P, Nachev C, O'Brien E, Rodicio JL, Rosenfeld J, Sarti C, Tuomilehto J, Webster J, Yodfat Y, Zanchetti A: Systolic Hypertension in Europe (Syst-Eur) Trial Investigators: Effects of immediate versus delayed antihypertensive therapy on outcome in the Systolic Hypertension in Europe Trial. J Hypertens 2004, 22:847-857.

37. UK Prospective Diabetes Study Group: Tight blood pressure control and risk of macrovascular and microvascular complications in type 2 diabetes: UKPDS 38. Br Med J 1998, 317:703-713.

38. Holman RR, Paul SK, Bethel MA, Neil HA, Matthews DR: Long-term followup after tight control of blood pressure in type 2 diabetes. N Engl J Med 2008, 359:1565-1576.

39. Tuomilehto J, Lindström J, Eriksson JG, Valle T, Hämäläinen H, llanne-Parikka P, Keinänen-Kiukaanniemi S, Laakso M, Louheranta A, Rastas M, Salminen V, Uusitupa M, Finnish Diabetes Prevention Study Group: Prevention of type 2 diabetes mellitus by changes in lifestyle among subjects with impaired glucose tolerance. N Engl J Med 2001, 344:1343-1350.

40. Lindström J, llanne-Parikka P, Peltonen M, Aunola S, Eriksson JG, Hemiö K, Hämäläinen $H$, Härkönen $P$, Keinänen-Kiukaanniemi S, Laakso $M$, Louheranta A, Mannelin M, Paturi M, Sundvall J, Valle T, Uusitupa M, Tuomilehto J, Finnish Diabetes Prevention Study Group: Sustained reduction in the incidence of type 2 diabetes by lifestyle-intervention: follow-up of the Finnish Diabetes Prevention Study. Lancet 2006, 368:1673-1679.

41. Uusitupa M, Peltonen M, Lindström J, Aunola S, llanne-Parikka P, KeinänenKiukaanniemi S, Valle TT, Eriksson JG, Tuomilehto J, Finnish Diabetes Prevention Study Group: Ten-year mortality and cardiovascular morbidity in the Finnish Diabetes Prevention Study-secondary analysis of the randomized trial. PLoS One 2009, 4:e5656.

42. Pan XR, Li GW, Hu YH, Wang JX, Yang WY, An ZX, Hu ZX, Lin J, Xiao JZ, Cao $H B$, Liu PA, Jiang $X G$, Jiang $Y Y$, Wang JP, Zheng $H$, Zhang $H$, Bennett $P H$, Howard BV: Effects of diet and exercise in preventing NIDDM in people with impaired glucose tolerance: the Da Qing IGT and Diabetes Study. Diabetes Care 1997, 20:537-544

43. Li G, Zhang P, Wang J, Gregg EW, Yang W, Gong Q, Li H, Li H, Jiang Y, An Y, Shuai Y, Zhang B, Zhang J, Thompson TJ, Gerzoff RB, Roglic G, Hu Y, Bennett $\mathrm{PH}$ : The long-term effect of lifestyle interventions to prevent diabetes in the China Da Qing Diabetes Prevention Study: a 20-year follow-up study. Lancet 2008, 371:1783-1789.

44. Knowler WC, Barrett-Connor E, Fowler SE, Hamman RF, Lachin JM, Walker EA, Nathan DM, Diabetes Prevention Program Research Group: Reduction in the incidence of type 2 diabetes with lifestyle intervention or metformin. N Engl J Med 2002, 346:393-403.

45. Knowler WC, Fowler SE, Hamman RF, Christophi CA, Hoffman HJ, Brenneman AT, Brown-Friday JO, Goldberg R, Venditti E, Nathan DM, Diabetes Prevention Program Research Group: 10-year follow-up of diabetes incidence and weight loss in the Diabetes Prevention Program Outcomes Study. Lancet 2009, 374:1677-1686.

46. Gaede $P$, Vedel $P$, Larsen $N$, Jensen $G V H$, Parving $H-H$, Pedersen $\mathrm{O}$ : Multifactorial intervention and cardiovascular disease in patients with type 2 diabetes. N Engl J Med 2003, 348:383-393.

47. Gaede $\mathrm{P}$, Lund-Andersen $\mathrm{H}$, Parving HH, Pedersen O: Effect of a multifactorial intervention on mortality in type 2 diabetes. $N$ Engl J Med 2008, 358:580-591.
48. Yamagishi S, Nakamura K, Imaizumi T: Advanced glycation end products (AGEs) and diabetic vascular complications. Curr Diabetes Rev 2005, 1:93-106.

49. Yamagishi S, Ueda S, Matsui T, Nakamura K, Okuda S: Role of advanced glycation end products (AGEs) and oxidative stress in diabetic retinopathy. Curr Pharm Des 2008, 14:962-968.

50. Yan SF, Ramasamy R, Bucciarelli LG, Wendt T, Lee LK, Hudson BI, Stern DM, Lalla E, DU Yan S, Rong LL, Naka Y, Schmidt AM: RAGE and its ligands: a lasting memory in diabetic complications?. Diab Vasc Dis Res 2004, 1:10-20.

51. Ihnat MA, Thorpe JE, Kamat CD, Szabó C, Green DE, Warnke LA, Lacza Z, Cselenyák A, Ross K, Shakir S, Piconi L, Kaltreider RC, Ceriello A: Reactive oxygen species mediate a cellular "memory" of high glucose stress signalling. Diabetologia 2007, 50:1523-1531.

52. El-Osta A, Brasacchio D, Yao D, Pocai A, Jones PL, Roeder RG, Cooper ME, Brownlee M: Transient high glucose causes persistent epigenetic changes and altered gene expression during subsequent normoglycemia. J Exp Med 2008, 205:2409-2417. Erratum in: J Exp Med 2008, 205:2683.

53. Siebel AL, Fernandez AZ, El-Osta A: Glycemic memory associated epigenetic changes. Biochem Pharmacol 2010, 80:1853-1859.

54. Pirola L, Balcerczyk A, Okabe J, El-Osta A: Epigenetic phenomena linked to diabetic complications. Nat Rev Endocrinol 2010, 6:665-675.

55. Villeneuve LM, Natarajan R: The role of epigenetics in the pathology of diabetic complications. Am J Physiol Renal Physiol 2010, 299:F14-F25.

56. Reddy MA, Natarajan R: Epigenetic mechanisms in diabetic vascular complications. Cardiovasc Res 2011, 90:421-429.

57. Villeneuve LM, Natarajan R: Epigenetic mechanisms. Contrib Nephrol 2011, 170:57-65

58. Schisano B, Tripathi G, McGee K, McTernan PG, Ceriello A: Glucose oscillations, more than constant high glucose, induce p53 activation and a metabolic memory in human endothelial cells. Diabetologia 2011, 54:1219-1226

59. Genuth S, Sun W, Cleary P, Sell DR, Dahms W, Malone J, Sivitz W, Monnier VM, DCCT Skin Collagen Ancillary Study Group: Glycation and carboxymethyllysine levels in skin collagen predict the risk of future 10year progression of diabetic retinopathy and nephropathy in the diabetes control and complications trial and epidemiology of diabetes interventions and complications participants with type 1 diabetes. Diabetes 2005, 54:3103-3111.

60. Lind M, Odén A, Fahlén M, Eliasson B: The shape of the metabolic memory of HbA1c: re-analysing the DCCT with respect to time-dependent effects. Diabetologia 2010, 53:1093-1098.

61. Jax TW: Metabolic memory: a vascular perspective. Cardiovasc Diabetol 2010, 9:51

62. Liao JK: Effects of statins on 3-hydroxy-3-methylglutaryl coenzyme A reductase inhibition beyond low-density lipoprotein cholesterol. Am J Cardiol 2005, 96(5A):24F-33F.

63. Elrod JW, Lefer DJ: The effects of statins on endothelium, inflammation and cardioprotection. Drug News Perspect 2005, 18:229-236.

64. Parati G, Bilo G, Ochoa JE: Benefits of tight blood pressure control in diabetic patients with hypertension: importance of early and sustained implementation of effective treatment strategies. Diabetes Care 2011, 34 (Suppl 2):S297-S303.

65. Mancia G, Laurent S, Agabiti-Rosei E, Ambrosioni E, Burnier M, Caulfield MJ, Cifkova R, Clément D, Coca A, Dominiczak A, Erdine S, Fagard R, Farsang C, Grassi G, Haller H, Heagerty A, Kjeldsen SE, Kiowski W, Mallion JM, Manolis A, Narkiewicz K, Nilsson P, Olsen MH, Rahn KH, Redon J, Rodicio J, Ruilope L, Schmieder RE, Struijker-Boudier HA, van Zwieten PA, Viigimaa M, Zanchetti $A$ : Reappraisal of European guidelines on hypertension management: a European Society of Hypertension Task Force document. $J$ Hypertens 2009, 27:2121-2158.

66. Ismail H, Mitchell R, McFarlane SI, Makaryus AN: Pleiotropic effects of inhibitors of the RAAS in the diabetic population: above and beyond blood pressure lowering. Curr Diab Rep 2010, 10:32-36.

67. Volpe M, Cosentino F, Tocci G, Palano F, Paneni F: Antihypertensive therapy in diabetes: the legacy effect and RAAS blockade. Curr Hypertens Rep 2011, 13:318-324.

68. Uusitupa M, Lindi V, Louheranta A, Salopuro T, Lindström J, Tuomilehto J, Finnish Diabetes Prevention Study Group: Long-term improvement in insulin sensitivity by changing lifestyles of people with impaired glucose tolerance: 4-year results from the Finnish Diabetes Prevention Study. Diabetes 2003, 52:2532-2538. 
69. de Mello VD, Lindström J, Eriksson J, Ilanne-Parikka P, Keinänen-Kiukaanniemi S, Sundvall J, Laakso M, Tuomilehto J, Uusitupa M: Insulin secretion and its determinants in the progression of impaired glucose tolerance to type 2 diabetes in impaired glucose-tolerant individuals: the Finnish Diabetes Prevention Study. Diabetes Care 2012, 35:211-217.

70. Ihnat MA, Thorpe JE, Ceriello A: Hypothesis: the "metabolic memory”, the new challenge of diabetes. Diabet Med 2007, 24:582-586.

71. Ceriello A: Hypothesis: the "metabolic memory", the new challenge of diabetes. Diabetes Res Clin Pract 2009, 86S:S2-S6.

72. Jermendy G: Late effect of treatment for reducing cardiovascular risk - a hypothesis on cardiometabolic therapeutic memory. Med Hypotheses 2009, 73:73-79.

73. Del Prato S: Megatrials in type 2 diabetes. From excitement to frustration?. Diabetologia 2009, 52:1219-1226.

74. Griffin SJ, Borch-Johnsen K, Davies MJ, Khunti K, Rutten GE, Sandbæk A Sharp SJ, Simmons RK, van den Donk M, Wareham NJ, Lauritzen T: Effect of early intensive multifactorial therapy on 5-year cardiovascular outcomes in individuals with type 2 diabetes detected by screening (ADDITIONEurope): a cluster-randomised trial. Lancet 2011, 378:156-167.

doi:10.1186/1475-2840-11-44

Cite this article as: Jermendy: Vascular memory: can we broaden the concept of the metabolic memory? Cardiovascular Diabetology 2012 11:44.

\section{Submit your next manuscript to BioMed Central and take full advantage of:}

- Convenient online submission

- Thorough peer review

- No space constraints or color figure charges

- Immediate publication on acceptance

- Inclusion in PubMed, CAS, Scopus and Google Scholar

- Research which is freely available for redistribution 